\title{
Determination of Antimony in Gunshot Residues Using GFAAS and SEM/EDX
}

\author{
Cagdas Aksoy a*, Yusuf Akman ${ }^{a}$, Zeynep Omca Ergun ${ }^{a}$, Ugur Uzek $^{\mathrm{b}}$, and Firat Aydin \\ ${ }^{a}$ Department of Chemical Analysis, Diyarbakir Police Criminal Laboratory, \\ 21010, Sehitlik, Diyarbakir, Turkey \\ b Department of Chemical Analysis, Ankara Police Criminal Laboratory, 06830, Golbasi, Ankara, Turkey \\ c Department of Chemistry, Sciences Faculty, Dicle University, 21280, Diyarbakir, Turkey
}

\section{INTRODUCTION}

Crimes involving the discharge of firearms are some of the most serious, and often fatal, incidents law enforcement agencies have to investigate (1). The United States of America is an example of a country with both high public and police gun possession. According to the United Nations Office on Drugs and Crime (UNODC), homicides involving guns in the USA are regularly above 10,000 annually, accounting for $66-68 \%$ of all homicides (2). Thus, growing security needs have generated major demands for effective field-deployable tools for the detection of gunshot residues (GSR) in a fast, reliable, and simple manner (3). Over the years, several studies have been performed on the detection of GSR on many types of materials and by various methods in order to provide an unambiguous definition of "gunshot residues" and to evaluate which procedures are the most reliable for their recognition and analysis $(4,5)$. Regarding the techniques used to detect gunshot residues, scanning electron microscopy coupled with energy dispersive X-ray analysis (SEM/EDX) is considered one of the most reliable tools because both morphological information and elemental composition of the particles can be obtained (6-10)

In 2010, the American Society for Testing and Materials (ASTM) established that the particles characteristic of GSR must contain lead, barium, and antimony, possibly with one or more of the following elements: aluminum, silicon, phos-

*Corressponding author

E-mail: cagdas_aksoy@botmail.com

\section{ABSTRACT}

Transferring gunshot residue via adhesive tape is a very applicable technique for the collection of firearm discharge residue from the surface of hands and face. In this study, antimony was determined in 15 types of adhesive tape and the false positive possibility in the results was investigated. Adhesive tapes, which were provided by crime scene investigators and from a regional market, were analyzed with a graphite furnace atomic absorption spectrometer as used in Police Criminal Laboratories.

In two samples, the measured antimony concentrations were 9.2 and $43.7 \mu \mathrm{g} \mathrm{L}^{-1}$, respectively, and high enough to cause false positives although most of the samples were clean. The source of antimony was detected via imaging and detailed elemental analysis of the samples. In addition, a simple method is proposed to prevent false positives. The method described is simpler, less costly, and faster than the modern approaches used for gunshot residue analysis and is based on the determination of antimony using GFAAS and SEM/EDX.

phorus, sulphur (trace), chlorine, potassium, calcium, iron (trace), nickel, copper, zinc, zirconium, and tin (1). GSR detection, therefore, represents a significant analytical challenge, requiring a detection technique that can sensitively and non-destructively image and analyze individual micron-sized particles (1). In addition, sample collection is a crucial step in the analysis of GSR $(11,12)$. Several dry and wet approaches are commonly employed for the collection of primer-metal residues such as tape lifts $(11,13,14)$, vacuum lifts $(11,13)$, and swabbing $(11,13-20)$, but they require centralized facilities to proceed with the analysis and are thus often confined to a laboratory.

Detection of residual materials from firearms is a common way to catch eventual shooters in forensic cases. In the Diyarbakir Police Criminal Laboratory, located in southeast Turkey, about 26,000 samples were analyzed in 2012 resulting in noticeable assistance to the investigators. When a cartridge round is fired in a firearm, combustion products from both the primer and the propellant will be released at the same time (21). Antimony $(\mathrm{Sb})$, lead $(\mathrm{Pb})$, and barium $(\mathrm{Ba})$, which are primer-sourced and the most common characteristic GSR elements, are generally determined by elemental analysis methods and also with imaging systems (22-25).

Antimony, which is the focus of this study, is found in several alloys, pyrotechnics, and polymers, and is used as a fire retardant in cotton and polyester blend fibers $(26,27)$. Thus, occupational groups interested in using these types of materials risk antimony contamination on the people's hands and faces (28). Transferring of GSR from the surfaces is one of the most important stages in an analysis. The transfer method must be simple, quickly applicable, reliable, and not harmful to human health. Some methods like swabbing with nitric acid are rarely considered despite good results $(29,30)$. The adhesive tape method provides an easy, rapid, and reliable way to collect GSR from surfaces and is widely used by 
crime scene investigators (31-34). There are various types of adhesive tapes that are generally used in the medical sector. Their adhesive feature makes them a good method for transferring solid particles from surfaces. The raw materials used to manufacture the tapes are mostly silk, cotton, and polyester.

In this research, we studied five different types of adhesive tapes commonly used by crime scene investigators and which are sold in the open market place. Antimony was selected for this study due to the lower contamination risk in comparison to $\mathrm{Pb}$ and $\mathrm{Ba}$.

Graphite furnace atomic absorption spectrometry (GFAAS) and scanning electron microscope/ energy dispersive X-Ray spectroscopy (SEM/EDX) were carried out for the determination of all of the elements of interest in gunshot residue.

\section{EXPERIMENTAL}

\section{Instrumentation}

A PerkinElmer ${ }^{\circledR}$ AAnalyst ${ }^{\mathrm{TM}} 600$ atomic absorption spectrometer, equipped with Zeeman background corrector, graphite furnace with THGA $^{\mathrm{TM}}$ pyrolytically coated graphite tubes, and a PerkinElmer AS-800 autosampler, were used (PerkinElmer, Inc., Shelton, CT,
USA). Integrated absorbance readings were performed under gas stop conditions during the atomization step. The operating conditions and analytical parameters are listed in Table I.

Imaging and other elemental analyses were carried out with a Jeol Jsm 6400 model SEM/EDX (Jeol Co., USA), and the operating conditions are listed in Table II.

\section{Standard Solutions and Reagents}

Antimony ( $\mathrm{Sb}$ ) standard solution of $1.000 \mathrm{mg} \mathrm{L}^{-1}$ for AAS was supplied by E. Merck (Darmstadt, Germany). Pure water was produced with a GFL 2204 water-purifier (GFL Co., Germany). Working standard solutions of 5,10, 20, and $45 \mu \mathrm{g} \mathrm{L}^{-1} \mathrm{Sb}$ in $1 \%$ nitric acid were prepared by dilution of the original $1000 \mathrm{mg} \mathrm{L}^{-1} \mathrm{Sb}$ standard. Nitric acid (65\%, Merck) and acetone (Merck) were of analytical purity.

\section{Sample Collection}

The adhesive tapes were purchased at regional markets and obtained from crime scene investigators located near Diyarbakir. A 9 mm Browning 1935 pistol (Belgium) with MKE 9x19 mm parabellum cartridges (Turkey) was used to simulate a person firing the pistol.

TABLE I

Instrumental Operating Conditions for Antimony Determination

\begin{tabular}{|c|c|c|c|}
\hline \multicolumn{2}{|c|}{ Instrumentation } & \multicolumn{2}{|c|}{ PerkinElmer ${ }^{\circledR}$ AAnalyst ${ }^{\mathrm{TM}} 600$ AAS } \\
\hline \multicolumn{2}{|c|}{ Lamp } & \multicolumn{2}{|c|}{ PerkinElmer ${ }^{\circledR}$ Lumina ${ }^{\mathrm{TM}} \mathrm{Sb}$} \\
\hline \multicolumn{2}{|c|}{ Wavelength } & $217.6 \mathrm{~nm}$ & \\
\hline \multicolumn{2}{|c|}{ Slit width } & $0.5 \mathrm{~nm}$ & \\
\hline \multicolumn{2}{|c|}{ Dispensed sample volume } & $20 \mu \mathrm{L}$ & \\
\hline Step & Temperature $\left({ }^{\circ} \mathrm{C}\right)$ & Ramp Time (s) & Hold Time (s) \\
\hline 1 & 110 & 1 & 20 \\
\hline 2 & 130 & 15 & 20 \\
\hline 3 & 1000 & 10 & 15 \\
\hline 4 & 2100 & 0 & 5 \\
\hline 5 & 2450 & 1 & 3 \\
\hline
\end{tabular}

\section{Atomic Apectroscopy 1 Vol. 34(5), Sept./Oct. 2013}

\section{Sample Preparation}

The analytical method still used as one of the GSR detection methods in the Diyarbakır Police Criminal Laboratory was the quantitative elemental detection of antimony via GFAAS (35). Fifteen different adhesive tapes were used for the analyses (see Table V, next page). Each sample was prepared to consist of a $25 \mathrm{~cm}^{2}$ surface area in order to simulate samples which are normally submitted for analysis by crime scene investigators. The sample boxes were of $2.5 \mathrm{~cm}$ bottom diameter, $4 \mathrm{~cm}$ height, and made of polystyrene (LP Italiana Spa, Italy). The samples were put into boxes and shaken for 45 minutes with $4 \mathrm{~mL} 8 \%$ nitric acid (v/v).

For adhesive content analysis, the samples were first washed with $10 \mathrm{~mL}$ acetone in an ultrasonic bath for two minutes. The acetone was vaporized and then dissolved in $4 \mathrm{~mL} \mathrm{8 \%} \mathrm{nitric} \mathrm{acid} \mathrm{(v/v)} \mathrm{for} \mathrm{Sb}$ determination. Adhesive-free tapes were also analyzed using the same method.

Swabs from the hands of shooters were taken five minutes after firing.

\section{RESULTS AND DISCUSSION}

A key piece of evidence left behind in shooting incidents, and which could help in this regard, is the gunshot residue (GSR) produced when a gun is fired. GSR is a heterogeneous cloud of propellant particles in various stages of combustion, in addition to the condensation particles originating from

\section{TABLE II}

SEM/EDX Operating Conditions for Adhesive Tape Analysis

\begin{tabular}{ll} 
Voltage & $15.0 \mathrm{kV}$ \\
Working distance & $39 \mathrm{~mm}$ \\
Takeoff angle & $35.0^{\circ}$ \\
Distance & $39 \mathrm{~mm}$ \\
Elapsed lifetime & $100.0 \mathrm{~s}$ \\
\hline
\end{tabular}


the metals used in the primer, cartridge, and projectile (4). Due to the organic makeup of the propellant, it has proven difficult to unambiguously identify GSR from the propellant residue, although various techniques have been reported to be good screening procedures $(5,6)$. Forensic analysts, therefore, typically use the inorganic compo- nents originating from the primer to detect GSR particles on a suspect. Inorganic GSR particles are typically of micron dimensions and normally collected with an adhesive lifter. This lifts not only the GSR particles, but also those of other environmental origin with which the shooter has come in contact (1).

TABLE III

Confidence Parameters Based on the Calibration Curve

$\begin{array}{ll}\text { \%RSD } & 3.332 \text { (for } 5 \mu \mathrm{g} \mathrm{L}^{-1}, 26 \text { samples) } \\ \mathrm{m} \text { (slope) } & 0.0017 \\ \mathrm{n} \text { (slide) } & 0.0031 \\ \text { Linear range } & 5-45 \mu \mathrm{g} \mathrm{L}^{-1} \\ \mathrm{~S} \text { (Standard deviation) } & 0.0003 \\ \mathrm{R}^{2} & 0.999 \\ \text { LOD } & 0.5844 \mu \mathrm{g} \mathrm{L}^{-1} \\ \text { LOQ } & 1.9480 \mu \mathrm{g} \mathrm{L}^{-1} \\ \text { CC } & 2.0374 \mu \mathrm{g} \mathrm{L}^{-1}\end{array}$

TABLE IV

Sb Concentrations of Samples at Different Shake Times $\left(\mu \mathrm{g}^{-1}\right)$

\begin{tabular}{cccccc}
\hline $\begin{array}{c}\text { Sample } \\
\text { No. }\end{array}$ & $30 \mathrm{~min}$. & $45 \mathrm{~min}$. & $60 \mathrm{~min}$. & $90 \mathrm{~min}$. & $120 \mathrm{~min}$. \\
\hline 3 & 8.6 & 9.2 & 9.3 & 9.6 & 9.7 \\
9 & 46.6 & 43.6 & 43.0 & 42.1 & 41.0 \\
\hline
\end{tabular}

TABLE V

GFAAS Analysis of Adhesive Tape Samples

\begin{tabular}{|c|c|c|}
\hline $\begin{array}{l}\text { Sample } \\
\text { No. }\end{array}$ & $\begin{array}{l}\text { Name and Type of } \\
\text { Adhesive Tape (AT) }\end{array}$ & $\begin{array}{c}\text { Mean Sb Conc. } \\
\left(\mu \mathrm{g} \mathrm{L}^{-1}\right)\end{array}$ \\
\hline 1 & A* Medical Fabric AT & $<\mathrm{LOD}$ \\
\hline 2 & B* Medical Silk AT & $<$ LOD \\
\hline 3 & $\mathrm{~B}^{*}$ Elastic Medical AT & 9.2 \\
\hline 4 & $\mathrm{~B}^{*}$ Medical Transparent AT & $<\mathrm{LOD}$ \\
\hline 5 & 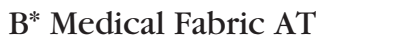 & $<$ LOD \\
\hline 6 & B* Medical Paper AT & $<\mathrm{LOD}$ \\
\hline 7 & C* Medical Fabric AT & $<$ LOD \\
\hline 8 & $C^{*}$ Medical Paper AT & $<\mathrm{LOD}$ \\
\hline 9 & $\mathrm{C}^{*}$ Elastic Medical AT & 43.6 \\
\hline 10 & D* Medical Silk AT & $<\mathrm{LOD}$ \\
\hline 11 & D* Medical Fabric AT & $<\mathrm{LOD}$ \\
\hline 12 & $\mathrm{E}^{*}$ Medical Paper AT & $<\mathrm{LOD}$ \\
\hline 13 & $\mathrm{E}^{*}$ Medical Transparent AT & $<\mathrm{LOD}$ \\
\hline 14 & $\mathrm{E}^{*}$ Medical Fabric AT & $<\mathrm{LOD}$ \\
\hline 15 & E* Medical Silk AT & $<$ LOD \\
\hline
\end{tabular}

In our study, the confidence parameters were based on the relative standard deviation (\%RSD), limit of detection (LOD), limit of quantitation (LOQ), and characteristic concentration (CC) values obtained by GFAAS from the calibration curves shown in Table III.

Five different shake times were studied to determine if there is any change in the $\mathrm{Sb}$ concentrations due to time and to make the method more efficient. The results in Table IV show that there was no significant difference above $30 \mathrm{~min}$ utes. Due to the short operating time, a 45-minute shake time was used for the method.

In the two samples numbered 3 and 9, the mean antimony concentrations were 9.2 and $43.6 \mu \mathrm{g} \mathrm{L}^{-1}$, respectively, which were high enough to cause false positives. Both samples were made of elastictype fiber. The sample trade name, type, and concentrations are listed in Table V.

Swabs taken from the hands of shooters and non-shooters were analyzed to establish the performance of the tapes. It was clear that both (blank and dirty) samples successfully collected GSR from the hands. In addition, significant differences in concentrations were found from the swabs of the shooters vs. the blank adhesive tapes. The mean concentrations and the difference between shooter swabs and the blank adhesive tapes are listed in Table VI.

TABLE VI

Comparison of Swabs From the Hands of Non-Shooters and Shooters

\begin{tabular}{|c|c|c|c|c|}
\hline $\begin{array}{c}\text { Sample } \\
\text { No. }\end{array}$ & $\begin{array}{l}\text { Blank } \\
\text { Adhesive } \\
\text { Tape } \\
\left(\mu \mathrm{g} \mathrm{L}^{-1}\right)\end{array}$ & $\begin{array}{l}\text { Non-- } \\
\text { Shooters } \\
\left(\mu \mathrm{g} \mathrm{L}^{-1}\right)\end{array}$ & $\begin{array}{r}\text { Shooters } \\
\left(\mu \mathrm{g} \mathrm{L}^{-1}\right)^{\mathrm{F}}\end{array}$ & $\begin{array}{c}\text { Difference } \\
\text { Between } \\
\text { Blank and Shooters } \\
\left(\mu \mathrm{g} \mathrm{L}^{-1}\right)\end{array}$ \\
\hline 3 & 9.2 & 9.5 & 80.2 & 71.0 \\
\hline 5 & $<\mathrm{LOD}$ & $<$ LOD & 65.1 & 65.1 \\
\hline 7 & $<$ LOD & $<$ LOD & 67.0 & 67.0 \\
\hline 9 & 43.6 & 44.0 & 88.3 & 44.7 \\
\hline 14 & $<$ LOD & $<$ LOD & 56.5 & 56.5 \\
\hline
\end{tabular}




\section{Atomic Apectroscopy \\ $\bigcirc$ Vol. 34(5), Sept./Oct. 2013}

A detailed imaging of the sample tapes numbered 3 and 9 was performed to determine the source of $\mathrm{Sb}$. The SEM images [Figures 1(a) and $1(b)]$ and the EDX results, which were focused on elastic-type fibers presenting the elemental combinations, are listed in Tables VII(A) and $\mathrm{VII}(\mathrm{B})$.

It can be seen that we have demonstrated a system that integrates the sampling and analysis of GSR from the hands of subjects discharging a firearm. We propose that this sample collection method shows much promise for a portable, field-deployable system aimed at rapidly identifying a subject who has loaded or discharged a firearm.

\section{CONCLUSION}

In the present study, emphasis was placed on the search of gunshot residue (GSR) using scanning electron microscopy coupled with energy dispersive X-ray analysis (SEM/EDX), one of the most reliable methods for the analysis of such residues. In addition, this study confirms the validity of SEM coupled with EDX in the analysis and characterization of gunshot residue, confirming previous studies concerning gunshot wounds on well-preserved material, and opens up interesting and new perspectives for the study of burnt materials.

Once again it has been shown that elemental analysis without particle imaging is not enough to determine antimony in GSR. In two blank samples, the antimony concentrations were high enough to cause false positives. There was no antimony found in the adhesives. The source of antimony was from the elastic-type adhesive tape fibers. Because antimony was within the structure of the fibers and equally distributed within the tape, comparable results were obtained in each analysis. Although it is possible to subtract the mean

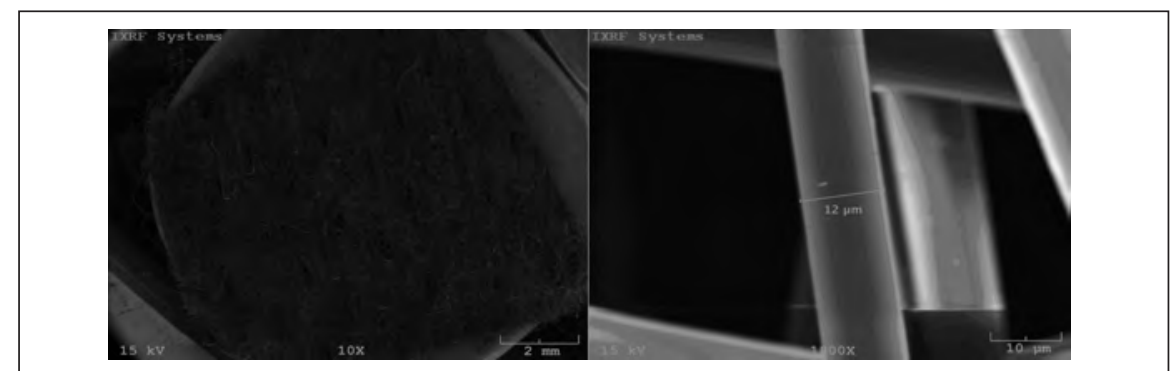

Fig. 1(a). Image of sample 3 and example of an EDX result.

TABLE VII (A)

SEM/EDX Results of Adhesive Tapes Containing Sb

\begin{tabular}{ccrrrl}
\hline Element & Line & $\begin{array}{c}\text { Intensity } \\
(\mathrm{c} / \mathrm{s})\end{array}$ & $\begin{array}{c}\text { Error } \\
2-\Sigma\end{array}$ & Conc. & Units \\
\hline $\mathrm{C}$ & $\mathrm{Ka}$ & 356,11 & 3,774 & 54,873 & wt.\% \\
$\mathrm{O}$ & $\mathrm{Ka}$ & 111,89 & 2,116 & 43,725 & wt.\% \\
$\mathrm{Cu}$ & $\mathrm{Ka}$ & 0,75 & 0,173 & 0,551 & wt.\% \\
$\mathrm{Zn}$ & $\mathrm{Ka}$ & 0,45 & 0,134 & 0,456 & wt.\% \\
$\mathrm{Sb}$ & $\mathrm{La}$ & 0,68 & 0,165 & 0,394 & wt.\% \\
\hline
\end{tabular}

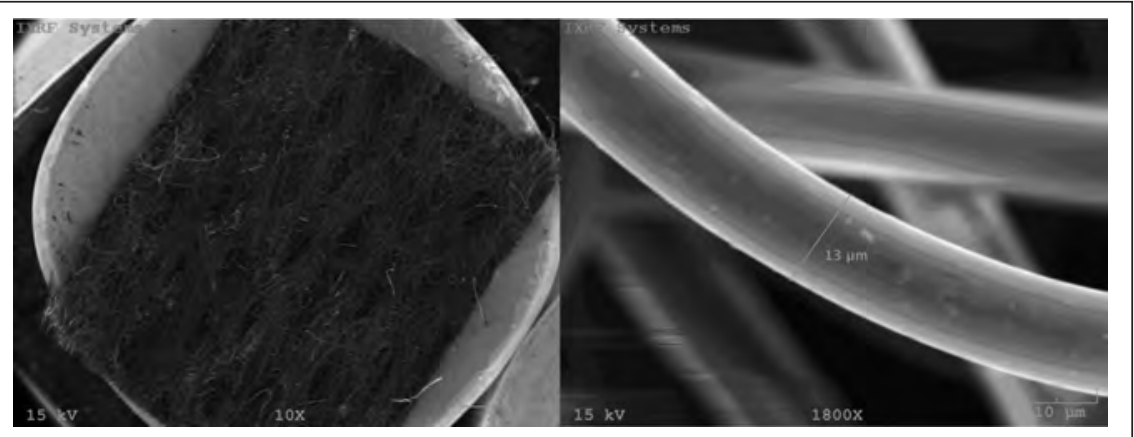

Fig. 1(b). Image of sample 9 and example of an EDX result.

TABLE VII (B)

SEM/EDX Results of Adhesive Tapes Containing Sb

\begin{tabular}{llrrrl}
\hline Element & Line & $\begin{array}{c}\text { Intensity } \\
(\mathrm{c} / \mathrm{s})\end{array}$ & $\begin{array}{c}\text { Error } \\
2-\Sigma\end{array}$ & Conc. & Units \\
\hline $\mathrm{C}$ & $\mathrm{Ka}$ & 156,62 & 2,503 & 52,253 & wt.\% \\
$\mathrm{O}$ & $\mathrm{Ka}$ & 57,98 & 1,523 & 44,904 & wt.\% \\
$\mathrm{Cu}$ & $\mathrm{Ka}$ & 1,00 & 0,200 & 1,512 & wt.\% \\
$\mathrm{Sb}$ & $\mathrm{La}$ & 0,56 & 0,150 & 0,660 & wt.\% \\
$\mathrm{Ti}$ & $\mathrm{Ka}$ & 0,82 & 0,181 & 0,299 & wt.\% \\
$\mathrm{Cl}$ & $\mathrm{Ka}$ & 0,87 & 0,187 & 0,186 & wt.\% \\
$\mathrm{Co}$ & $\mathrm{Ka}$ & 0,21 & 0,093 & 0,186 & wt.\% \\
\hline
\end{tabular}


concentrations and estimate the presence of antimony, it is recommended that crime scene investigators do not use these types of adhesive tapes. In addition, this method is not to be applied as a primary investigative technique but rather as a complimentary procedure to support and improve the evidential value of contemporary SEM-EDX systems. This study represents a large advance in the field of gunshot residue analysis and could potentially be invaluable in highly contested cases involving suspects who have been arrested by firearms officers.

\section{ACKNOWLEDGMENTS}

The authors are grateful to Hayrettin Dursun (Ankara Police Criminal Laboratory, Turkey) who performed the SEM/EDX analyses.

Received June 5, 2013.

\section{REFERENCES}

1. J.W. Warmenhoven A dissertation submitted to the Physics Department at the University of Surrey in partial fulfillment of the degree of Master in Physics University of Surrey, U.K. (February 2013).

2. Homicides by firearms, United Nations Office on Drugs and Crime [UNODC] (2013).

3. A.M. O'Mahony, J.R. Windmiller, I.A. Samek, A. J. Bandodkar, and J. Wang, Electrochem. Communications 23, 52 (2012).

4. F.S. Romolo, and P. Margot, Forensic Sci. Int. 119(2), 195 (2001).

5. O. Dalby, D. Butler, and and J.W. Birkett, J. Forensic Sci. 55(4), 924 (2010).

6. J. Lebiedzik, and D.L. Johnson, J. Forensic Sci. 45(1), 83 (2000).

7. Z. Brozek-Mucha, and A. Jankowicz, Forensic Sci. Int. 123(1), 39 (2001)

8. S. Kage, K. Kudo, Kaizoji et al., J. Forensic Sci. 46(4) 830 (2001).

9. Z. Brozek-Mucha, and G. Zadora Forensic Sci. Int. 135(2), 97 (2003)

10. D.K. Molina, M. Martinez, J. Garcia, and V.J. DiMaio, Am. J. Forensic Med. Pathol. 28(3), 187 (2007).

11. O. Dalby, D. Butler, and J.W. Birkett, J. Forensic Sci. 55, 924 (2010).

12. H.H. Meng, and B. Caddy, J. Forensic Sci. 42, 553 (1997).

13. F.S. Romolo, and P. Margot, Forensic Sci. Int. 119, 195 (2001).

14. S. Erden, Z. Durmus, and E. K1lıç, Electroanalysis 23, 1967 (2011).

15. C.A. Woolever, and H.D. Dewald, Forensic Sci. Int. 117, 185 (2001).

16. J.H. Liu, W.-F. Lin, and J.D. Nicol, Forensic Sci. Int. 16, 53 (1980).

17. C.A. Woolever, D.E. Starkey, and H.D. Dewald, Forensic Sci. Int. 102, 45 (1999).

18. R.C. Briner, S. Chouchoiy, R.W. Webster, and R.E. Popham, Anal. Chim. Acta 172, 31 (1985).

19. D.B. Dahl, and P.F. Lott, Microchem. J. 101, 49 (2012).
20. J.A. Rodriguez, I.S. Ibarra, C.A Galan-Vidal, M. Vega, and E. Barrado, Electroanal. 21, 452 (2009).

21. T.A. Warlow, Firearms, United Kingdom: Routledge (1996).

22. H.C. Harrison, and R. Gilroy, J. Forensic Sci. 4, 184 (1959).

23. S.S. Krishnan, J. Forensic Sci. 16, 144 (1971).

24. I.C. Stone, and C.S. Petty, J. Forensic Sci. 19, 784 (1974).

25. K. Zih-Perényi, P. Jankovics, É. Sugár, and A. Lásztity, Spectrochim. Acta Part B 63, 445 (2008).

26. G.S.Brady, and H.R.Clauser, Materials Handbook, 13th ed., McGraw-Hill, New York (1991).

27. O. Dalby, D. Butler, and J.W. Birkett, J. Forensic Sci. 55/4 (July 2010).

28. D.G. Havekost, C.A. Peters, and R.D. Koons, J. Forensic Sci. 35, 1096 (1990).

29. R.C. Briner, S. Chouchoiy, R.W. Webster, and R.E. Popham, Anal. Chim. Acta 172, 31 (1985).

30. C.A. Woolever, D.E. Starkey, and H.D. Dewald, Forensic Sci. Int. 102, 45 (1999).

31. R.L. Singer, D. Davis, and M. Houck, J. Forensic Sci. 41(2), 195 (1996).

32. M. Tassa, N. Adan, N. Zeldes, and Y. Leist, J. Forensic Sci. 27, 671 (1982).

33. H.A. Wrobel, J.J. Millar, and M. Kijek, J. Forensic Sci. 43, 178 (1998).

34. D.K. Shaffer and K. Yi, Scanning Conference 99, 21(2), 99 (1999).

35. Method validation of antimony analyses with atomic absorption spectrometry in gunshot residue, Ankara Police Criminal Laboratory, KPL-GP-021, Validation Report (2007). 